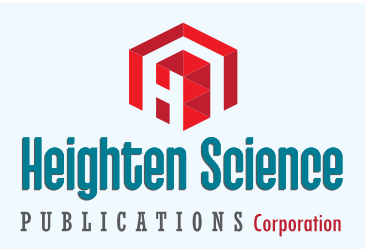

ISSN

2639-6777
*Address for Correspondence: Khadiga Ahmed Ismail, Laboratory Medicine Department,

Faculty of Applied Medical Sciences,

Taif University, Taif, Saudi Arabia, Tel:

009660507921103; Email:

khadigaahmed68@yahoo.com

Submitted: 06 December 2018

Approved: 10 January 2019

Published: 11 January 2019

Copyright: @ 2019 Hagag HM, et al. This is an open access article distributed under the Creative Commons Attribution License, which permits unrestricted use, distribution, and reproduction in any medium, provided the original work is properly cited

Keywords: Papanicolaou smears; Trichomonas vaginalis; Microscopy

Check for updates
Research Article

\section{Perinuclear halo indicate Trichomonas vaginalis in Pap smear}

\author{
Howaida Mahmoud Hagag1,2, Yosra Hussein Alam-Eldin ${ }^{3}$, \\ Mahmoud Khalifa Mahmoud ${ }^{4}$, Khadiga Ahmed Ismail ${ }^{1.3 *}$, \\ Amany Mamdouh Abdulaziz ${ }^{5}$, Ahmed Mahmoud Khalifa ${ }^{6}$ and \\ Osama Mahmoud Khalifa ${ }^{7}$ \\ 'Laboratory Medicine Department, Faculty of Applied Medical Sciences, Taif University, Taif, \\ Saudi Arabia \\ ${ }^{2}$ Pathology Department, Faculty of Medicine, Al-Azhar University, Cairo, Egypt \\ ${ }^{3}$ Medical Parasitology Department, Faculty of Medicine Ain Shams University, Cairo, Egypt \\ ${ }^{4}$ Consaltant of Dermatology and Venereology King Faisal specialized Hospital, Taif, Saudi Arabia \\ ${ }^{5}$ Pathology Department, Faculty of Medicine, Beni-Suef University, Beni-Suef, Egypt \\ ${ }^{6}$ Forensic and Toxicology Department Faculty of Medicine, Ain-Shams University, Cairo, Egypt \\ ${ }^{7}$ Faculty of Medicine, Ain-Shams University, Cairo, Egypt
}

\section{Abstract}

Trichomonas vaginalis could be seen in Pap smears where it is reported, but because main concerned is placed on malignant cells in Pap smears, not much effort is done to search for this parasite in smears. In this study, 100 cervical and vaginal specimens were examined microscopically by the conventional Papanicolaou method and liquid base cytology (LBC) for the presence of Trichomonas vaginalis (T.vaginalis). $16 \%$ were infected with T.vaginalis while $10 \%$ of diagnosis based on both perinuclear halo and $T$. vaginalis presence although the association between perinuclear halo and $T$, vaginalis is statistically insignificant it is recommended to increase the number of the cases to prove or disprove the association.

\section{Introduction}

Trichomoniasis is one of the most common sexually transmitted infections (STIs) but it has received little attention and has been trivialized. Despite being a readily diagnosed and treatable sexually transmitted disease (STD). World Health Organization estimated that there were 276.4 million cases in 2008 and nearly $90 \%$ of these infections occurred among people living in resource-limited settings [1].

Presumably, prevalence of infection with trichomoniasis is not a reportable infection, and control of the infection has received relatively little emphasis from public health STD control programs, however, appreciation of the high rates of disease and of associations of trichomoniasis in women with adverse outcomes of pregnancy and increased risk for human immunodeficiency virus HIV infection suggest a need for increased control efforts [2].

In Islamic countries, the prevalence of trichomoniasis ranges from $1.2 \%$ in Libya and Jordanto 3.2\% in Turkeyto $28.1 \%$ in Saudi Arabia [3].

Trichomoniasis is more common in women than men because men have asymptomatic infections. For women, the symptoms are thin frothy, green-yellow vaginal discharge, vulvovaginal irritation, vaginal soreness, and redness of the vagina, women also have a higher prevalence of invasive cervical cancer when they have trichomoniasis [4].

How to cite this article: Hagag HM, Alam-Eldin $\mathrm{YH}$, Mahmoud MK, Ismail KA, Abdulaziz AM, et al. Perinuclear halo indicate Trichomonas vaginalis in Pap smear. Arch Biotechnol Biomed. 2019; 3: 001005. https://doi.org/10.29328/journal.abb.1001013 
Vaginitis Common signs and symptoms of acute infection include a purulent, malodorous, thin discharge associated with burning, pruritus, dysuria, frequency, lower abdominal pain, or dyspareunia. Symptoms may be worse during menstruation Postcoital bleeding can occur [5].

Physical examination often reveals erythema of the vulva and vaginal mucosa. The classically described green-yellow, frothy, malodorous discharge occurs in 10 to 30 percent of symptomatic women. Punctate hemorrhages may be visible on the vagina and cervix ("strawberry cervix" in 2 percent of cases).In chronic infection, signs and symptoms are milder and may include pruritus and dyspareunia, with scanty vaginal secretion. In men, T. vaginalis infection is asymptomatic in over three-quarters of cases and often transient (spontaneous resolution within 10 days) [4], However, untreated infection can persist for months Symptoms, when present, are the same as those for urethritis from any cause and consist of a clear or mucopurulent urethral discharge and/or dysuria. They may also have mild pruritus or burning sensation in the penis after sexual intercourse [6].

The objective of this study is to determine the value of perinuclear halo in prediction of $T$. vaginalis infection using PAP smear in Saudi females patients. In Al-Taif KSA.

\section{Subjects and Methods}

Retrospective study was carried out in Al-Taif hospitals, permission to conduct the study was granted by the Ethics Committee of Al-Taif University. Preparation of slides for microscopic examination using conventional Papanicolaou method (PAP stain) and liquid base cytology (LBC) of one hundred female patients their age range from 20 to 50 years.

\section{Papanicolaou method}

Each specimen was smeared on a clean grease free slide and fixed in ether-alcohol for 30 minutes. The specimens were then stained by the Papanicolaou method as follows: Harris's haematoxylin without acetic acid for 5 minutes, rinsed in tap water and differentiated in $1 \%$ acid alcohol for 30 seconds and water for 2 minutes. Smears were taken to 95\%alcohol and stained in Orange G 6 for 2 minutes, rinsed in 95\% alcohol and stained in Eosin 35 for 2minutes. Smears were then taken to two changes of absolute alcohol, xylene and mounted in DPX. The stained smears were examined under the light microscope at low and high power objectives for the presence of T.vaginalis and perinuclear halo.

LBC had been performed with a plastic spatula and a Cytobrush material from endocervix has been obtained from all the investigated patients. Liquid-based monolayer specimens have been immersed in PreserveCyt solution and have been processed with Thin Prep 2000 processor (Cytyc Corporation, Boxborough, Massachusetts, USA). All the slides have been stained with Pap staining.

The stained slides had been examined using the microscope ( $\times 10$ objective), for a general view, by evaluating the staining quality, the cellularity, the acellular material, the bacterial flora and the T.vaginalis, and then with $\times 40$ objective for morphological details identification, avoiding the cellular overlaps and crowding that may result in errors of interpretation of chromatin features, of nuclear cytoplasmic rate and of cytoplasmic basophilia. The microscopic examination aimed the pathological alterations that appear in smear cellular features, guiding the cytopathologist in the diagnosis of non-neoplastic, inflammatory, preneoplastic, preinvasive and invasive tumors. LBC has been considered as significant if the slide contained more than 5000 epithelial cells. Endocervical cells have been considered as present if two or more glandular/ metaplastic cell groups, each of at least five cells or if the slide contained at least 10 glandular/metaplastic cells. 


\section{Results}

Figures 1-5; Table 1

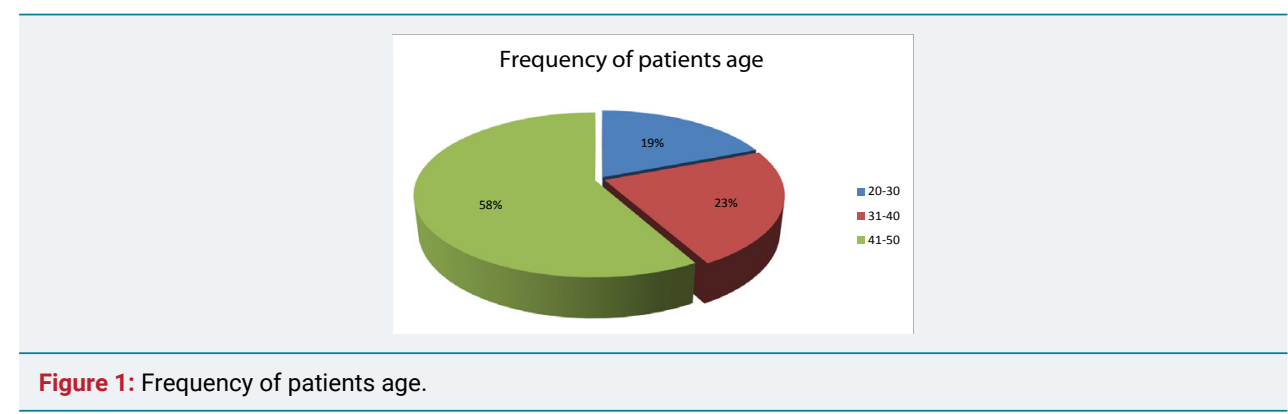

Figure 1: Frequency of patients age.

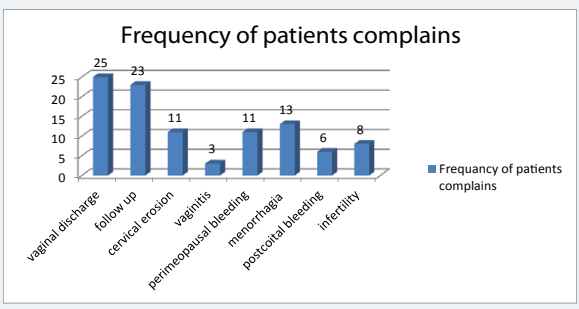

Figure 2: Frequency of patients complains.

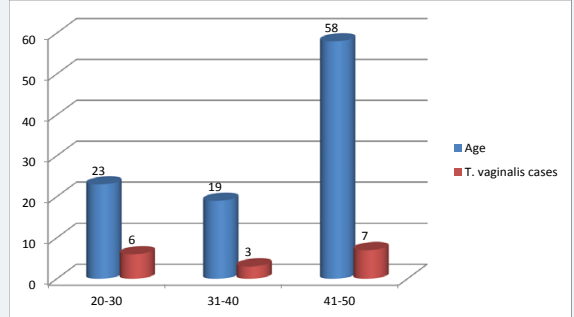

Figure 3: Frequency of T.vaginalis positive cases in differente age groups

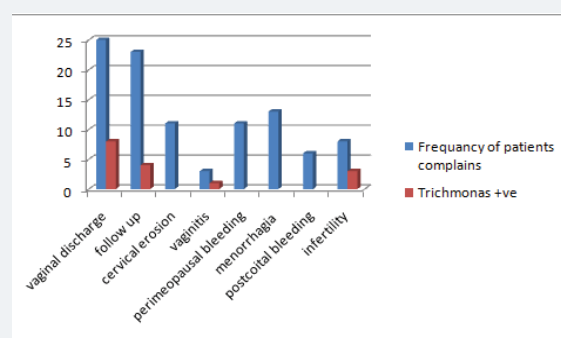

Figure 4: Frequency of trichomoniasis positive cases with patient complains

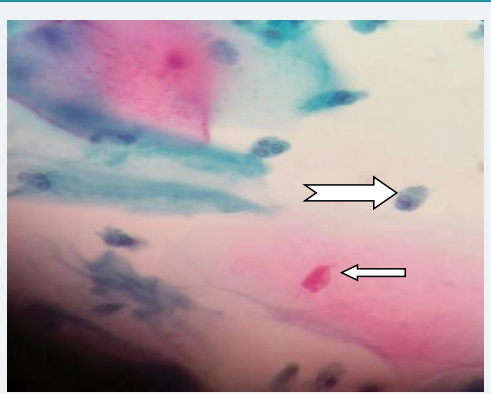

Figure 5: This Pap stained smear examined showing T. vaginalis organism (thick arrow) and faint perinuclear halo in superficial ectocervical cell (thin arrow). 


\section{Discussion}

Papanicolaou is the best staining method in cytology, because it helps to effectively differentiate malignant cells from non-malignant cells. It also stains the cytoplasm and its contents [7]. Its ability to differentiate acidophilic materials from basophilic materials as well as its ability to stain non-cellular substances such as fibrin, crystals and pigments, makes it an essential stain in cytology [8]. T. vaginalis, the causative organism for trichomoniasis is the most common curable sexually transmitted organism worldwide [9]. It parasitizes both males and females where it is sometimes asymptomatic in the early stages of the infection. T. vaginalis infection is said to play a role in the development of cervical neoplasia, postoperative infections, and adverse pregnancy outcomes and as a factor in atypical pelvic inflammatory disease and infertility [10].

There is also epidemiological and experimental evidence that Pap smears are beneficial in detecting infections that are risk factors associated with cervical cancer, such as human papilloma virus [11].

Several methods of diagnosis of trichomoniasis exist. There is the easiest method which involves examination of a wet preparation under the microscope where the organisms are seen moving rapidly in all directions. Other methods include overnight culture [12], rapid antigen testing, and transcription-mediated amplification and by PCR [13]. In this study Papanicolaou stained smears were examined and compared with results of the presence of perinuclear halo in the epithelial cells was used as a presumptive diagnosis for T. vaginalis. While T. vaginalis should be reported in cervical and vaginal Pap smears, its absence in these smears is not an indication for absolute absence of the organism in the patient.

In this study, Papanicolaou stained smears were examined and compared with results of the presence of perinuclear halo in the epithelial cells was used as a presumptive diagnosis for T. vaginalis. Pap smears show perinuclear halo which were insignificant in the detection of T. vaginalis as shown in tables 1 .this is agree with the result of Avwioro, 2002.

Our results showed $16 \%$ frequency of T. vaginalis in examined cases and this is correlated with its prevalence in Islamic country and in Saudi Arabia as suggested by Sobel et al., 2001. The apparent difference may be due to limited area in which the study completed.

Also our results showed prevalence of trichomoniasis in age group from 41 to 50 years. Also more prevalent with patient complains including vaginal discharge, infertility and vaginitis respectively and this is correlated with the previous studies that suggested that $T$. vaginalis form the important cause of pelvic infection and its sequel as infertility.

\begin{tabular}{|c|c|c|c|c|c|}
\hline & & \multicolumn{3}{|c|}{ PAP smear with perinuclear halo } & \multirow{2}{*}{$\begin{array}{c}\text { Statistical } \\
\text { Analysis }\end{array}$} \\
\hline & & Positive & Negative & Total & \\
\hline \multirow[t]{2}{*}{ PAP smear } & Positive & 10 & 6 & 16 & \multirow{3}{*}{$\begin{array}{c}X^{2}=10 \\
P>0.05^{\star}\end{array}$} \\
\hline & Negative & 4 & 80 & 84 & \\
\hline 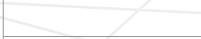 & & 14 & 86 & 100 & \\
\hline \multicolumn{2}{|c|}{${ }^{*} \mathrm{P}>0.05=$ Insignificant difference. } & \multicolumn{3}{|c|}{ 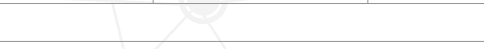 } & \\
\hline
\end{tabular}

\section{References}

1. World Health Organization. Global incidence and prevalence of selected curable sexually transmitted infections. 2008; 20. Ref.: https://goo.gl/Hvg13n

2. Sobel J, Nyirjesy $P$, Brown W. Tinidazole therapy for metronidazole-resistant vaginal trichomoniasis. Clin Infect Dis. 2001; 33: 1341-1346. Ref.: https://goo.gl/daahyP 
3. Dharma MN, Umashankar KM, Sudha AN, Kavitha G. Prevalence of the Trichomonas Vaginalis Infection in A Tertiary Care Hospital in Rural Bangalore, Southern India. J Clin Diagn Res. 2013; 7: 1401-1403. Ref.: https://goo.gl/tdhAPm

4. Seña AC, Miller WC, Hobbs MM, Schwebke JR, Leone PA, et al. Trichomonas vaginalis infection in male sexual partners: implications for diagnosis, treatment, and prevention. Clin Infect Dis. 2004; 44: 13. Ref.: https://goo.gl/8gJcZP

5. Heine P, McGregor JA. Trichomonas vaginalis: a reemerging pathogen. Clin Obstet Gynecol. 1993; 36: 137-144. Ref.: https://goo.gl/ytF73A

6. Cudmore SL, Delgaty KL, Hayward-McClelland SF, Petrin DP, Garber GE. Treatment of infections causad by metronidazole-resistant Trichomonas vaginalis. Clin Microbiol Rev. 2004; 17: 783-793. Ref.: https://goo.gl/MTDn2o

7. Avwioro 0. Histochemistry and tissue pathology. 2nd ed. Claverianun press Nigeria. 2010;

8. $\mathrm{Og} \mathrm{A}, \mathrm{Oe} \mathrm{O}, \mathrm{To} A$. Sensitivity of a papanicolaou smear in the diagnosis of candida albicans infection of the cervix. N Am J Med Sci. 2010; 2: 97-99. Ref.: https://goo.gl/5jmgbr

9. Soper D. Trichomoniasis: under control or under controlled? Am J Obstet Gynecol. 2004; 190: 281 290. Ref.: https://goo.gl/J89xfr

10. Schwebke JR, Burgess D. Trichomoniasis. Clinical Microbiology Reviews. 2004; 17: 794-803. Ref.: https://goo.gl/Sdpnrn

11. Schiffman MH, Bauer HM, Hoover RN, Glass AG, Cadell DM. Epidemiological evidence showing that human papillomavirus infection causes most cervical intraepithelial neoplasia. J Natl Cancer Inst. 1993; 85: 958-964. Ref.: https://goo.gl/19yHWp

12. Sood S, Mohanty S, Kapil A, Tolosa J, Mittal S. In Pouch TV culture for detection of Trichomonas vaginalis. Indian J Med Res. 2007; 125: 567-571. Ref.: https://goo.gl/hafqDV

13. Huppert JS, Mortensen JE, Reed JL, Kahn JA, Rich KD, et al. Rapid Antigen Testing Compares Favorably with Transcription-Mediated Amplification Assay for the Detection of Trichomonas vaginalis in Young Women. Clin Infect Dis. 2007; 45: 194-198. Ref.: https://goo.gl/g5SS5x 